\section{Why should we perform a D2 lymphadenectomy in gastric cancer?}
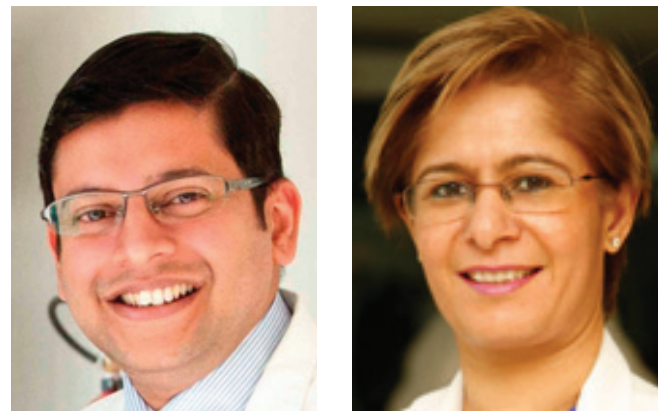

\author{
“...performance of a D2 \\ lymphadenectomy certainly \\ provides the maximal benefit \\ that can be achieved from a \\ lymphadenectomy in gastric \\ cancer for stages $\geq \mathrm{B}$."
}

Savio George Barreto ${ }^{1,2}$ \& Bhawna Sirohi*,3

First draft submitted: 21 June 2017; Accepted for publication: 26 June 2017;

Published online: 6 October 2017

Gastric cancer is the fourth most common cancer in the world [1]. Surgery offers the best chance for cure [2]. However, although the last decade has witnessed an increase in the number of surgical resections coupled with a fall in operative mortality rates [3], the overall 5 -year survival for gastric cancer remains at a meagre 20\% [4]. Gastric cancer accounts for $10 \%$ of cancer-related deaths worldwide [5] and thus, there is a need to focus on strategies aimed at reducing cancer-related mortality and improving overall survival.

The performance of a D2 lymphadenectomy in gastric cancer has been a matter of intense surgical research over the last 3 decades. This is based on the appreciation that lymph node metastasis is the most important prognostic factor in gastric cancer [6]. It has been hypothesized that an adequate lymphadenectomy enables an accurate staging of the disease, reduces the incidence of locoregional recurrences and thus contributes to an improved overall survival.
To ascertain if there exists a role for D2 lymphadenectomy in the management of gastric cancer, we adopted an evidence-based approach by following a logical sequence that aimed to dissect out the very reason we perform a lymphadenectomy in gastric cancer.

\section{- To achieve an accurate staging of the disease}

Karpeh et al. [7] carried out an analysis of data from more than a 1000 patients and determined that survival estimates based on number of involved lymph nodes in gastric cancer were better represented when 15 or more nodes were submitted for pathological examination. Nearly a decade later, the American Joint Committee for Cancer staging $[8]$ in their 7 th edition conceded that it was not possible to categorize the N3b stage if less than 16 nodes were assessed at histopathology. Xu et al. [9] went on to confirm that patients undergoing a D2 dissection should have at least 16 lymph nodes examined, especially in advanced

'Hepatobiliary \& Oesophagogastric Unit, Division of Surgery \& Perioperative Medicine Flinders Medical Centre, Bedford Park, Adelaide, South Australia - Australia

${ }^{2}$ School of Medicine, Faculty of Medicine, Nursing \& Health Sciences, Flinders University, South Australia - Australia

${ }^{3}$ Department of Medical Oncology, Barts Cancer Institute, Queen Mary University of London, London, UK

*Author for correspondence: bhawna.sirohi13@gmail.com

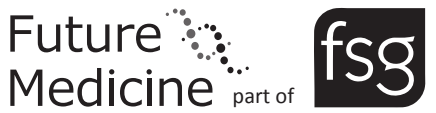




\author{
“... an extensive \\ lymphadenectomy can \\ improve disease-specific \\ survival in resectable \\ gastric cancer...”
}

disease. Thus, it would seem fair to infer that for an accurate histopathological assessment of every stage of gastric cancer, a minimum of 16 lymph nodes would be required.

\section{- To reduce the risk of locoregional recurrence}

An analysis of literature from 1982 to date indicates that locoregional recurrence rates following surgery for gastric cancer vary from as low as $7.1 \%$ [10] to as high as $87.8 \%$ [11]. The authors have previously demonstrated that 22 patients, out of a total of 126 , who received neoadjuvant chemotherapy (as part of their perioperative chemotherapy regimen) and subsequently underwent a D2 lymphadenectomy, were found to have a complete pathological response of the primary tumor [12]. However, 55\% of these patients had residual tumor detected in their lymph nodes indicating the lack of effect of chemotherapy on malignant lymph nodes. This finding supports the need to perform a complete lymphadenectomy even in patients receiving neoadjuvant chemotherapy. The question remains, 'what is an adequate lymphadenectomy to reduce locoregional recurrence'? Data from the Dutch trial confirmed that significantly more patients in the D1 arm had local recurrences at the time of their death compared with those who underwent a D2 lymphadenectomy (41 vs 30\%; p < 0.05) [13]. Schwarz and Zagala-Nevarez objectively demonstrated that performing a radical lymphadenectomy with a median lymph node yield of 24 reduced locoregional recurrence rates in their patient population down to 3\% [14] - the lowest reported to date. Thus, the best published evidence suggests the performance of a lymphadenectomy that includes a median of $24 \mathrm{lymph}$ nodes to significantly locoregional recurrence.

\section{- To improve survival (disease-specific \& overall)}

Gholami et al. [15] interrogated the databases of seven major American Academic centers and determined that a lymphadenectomy that included more than 16 lymph nodes resulted in a better disease-specific survival across stages IA through to IIIA. Prof. Siewert from Germany [16] had earlier demonstrated from his series of 1654 patients that performing a radical lymphadenectomy that included more than 25 lymph nodes conferred a significant survival advantage across stages II to IIIA. Lee et al. [17] from South Korea analyzed the data of 4789 patients with gastric cancer and found out that survival, especially for patients with stage IIIB disease, was better when the resected specimen contained more than 35 lymph nodes compared with those with less than 20 lymph nodes. The authors stated that this improvement in survival was due to a better surgical control of the disease rather than merely a result of stage migration. Furthermore, an analysis of 3814 patients from the SEER database [18] indicated that for every 10 extra lymph nodes dissected, the calculated overall survival improved by $7.6 \%$ (for T1/2N0), $5.7 \%$ (for $\mathrm{T} 1 / 2 \mathrm{~N} 1$ ), $11 \%$ (for T3N0), or $7 \%$ (for T3N1) up to a maximum of 40 dissected lymph nodes. Thus, to improve survival across all stages of gastric cancer, dissection of up to 40 lymph nodes appears necessary.

\section{- Echelons \& lymph node yield}

The extent of lymphadenectomy in gastric cancer has been defined as per the Japanese Gastric Cancer Association [19]. Simply put, the extent (D1, D2, D3) corresponds to removal of the first, second and third echelons of lymph nodes surrounding the stomach. Wagner and colleagues carried out a systematic study of the gastric lymph node basins in 30 cadavers and determined that median numbers of lymph nodes in each echelon (as defined by the Japanese Research Society for Gastric Cancer) were 17, 27 and 43, respectively [20]. This roughly corroborates with the lymph node yield following a D1, D2 and D3 lymphadenectomy.

Thus, to accurately stage gastric cancer (16 nodes), reduce the risk of locoregional recurrence ( 24 nodes) and to improve survival (up to 40 nodes), the performance of a D3 (or D2 with para-aortic nodal dissection) lymphadenectomy would seem to be the ideal procedure. But does the clinical evidence in literature support this?

\section{- Outcomes following lymphadenectomy}

The evidence indicates that an extensive lymphadenectomy can improve disease-specific survival in resectable gastric cancer $[13,21,22]$, suggesting a benefit of D2 as compared with D1 lymphadenectomy. Further, a meta-analysis of the data on lymphadenectomy indicates that a D2 lymphadenectomy with spleen and pancreas preservation offers the most survival benefit for patients with gastric cancer [21]. The problems linked to the performance of a D2 lymphadenectomy in the initial randomized trials included an increased risk of morbidity and mortality [23-27]. We now 
know that the increase in morbidity and mortality were likely the result of problems in training of the surgeons participating in the trial, the technique of lymphadenectomy (unnecessary addition of pancreatectomy and splenectomy), case selection, as well as noncompliance in the D2 dissection group [28,29]. Additionally, the safety of D2 lymphadenectomy has now been confirmed even in the context of neoadjuvant chemotherapy [12].

However, would performance of D3 (or D2 with para-aortic nodal dissection) lymphadenectomy be more effective than a D2 [30]. The most recent Cochrane review clarifies the subject based on a meta-analysis (of randomized controlled trials) comparing D2 with D3 lymphadenectomy (or $\mathrm{D} 2$ with para-aortic nodal dissection). The review has concluded that there is neither a significant difference in postoperative mortality, nor in disease-free and overall survival between the two procedures [22].

The final question that remains is, 'Should a D2 lymphadenectomy be performed in all patients with gastric cancer including early gastric cancer?' The authors recently revisited the definition of early gastric cancer that was unchanged since 1971 [31] despite advances in our understanding of the pathogenesis of the disease and its management. Based on a review of all published data, a new definition of early gastric cancer was proposed [32]. Based on the present definition of early gastric cancer [32], with the attendant likelihood of node-negative disease, performance of a D2 lymphadenectomy would be unnecessary for this stage of the disease. This view has been ratified by almost all the published guidelines around the world [33].

Based on a logical and systematic review of the evidence in literature, performance of a D2 lymphadenectomy certainly provides the maximal benefit that can be achieved from a lymphadenectomy in gastric cancer for stages $\geq \mathrm{IB}$.

\section{Financial \& competing interests disclosure}

The authors have no relevant affiliations or financial involvement with any organization or entity with a financial interest in or financial conflict with the subject matter or materials discussed in the manuscript. This includes employment, consultancies, honoraria, stock ownership or options, expert testimony, grants or patents received or pending, or royalties.

No writing assistance was utilized in the production of this manuscript.

\section{References}

1 Torre LA, Bray F, Siegel RL, Ferlay J, Lortet-Tieulent J, Jemal A. Global cancer statistics, 2012. CA Cancer J. Clin. 65(2), 87-108 (2015).

2 Sasako M. Principles of surgical treatment for curable gastric cancer. J. Clin. Oncol. 21(Suppl. 23), S274-S275 (2003).

3 Young JA, Shimi SM, Kerr L, Mcphillips G, Thompson AM. Reduction in gastric cancer surgical mortality over 10 years: an adverse events analysis. Ann. Med. Surg. (Lond.) 3(2), 26-30 (2014).

4 Correa P. Gastric Cancer: overview. Gastroenterol. Clin. North Am. 42(2), 211-217 (2013).

5 Fock KM. Review article: the epidemiology and prevention of gastric cancer. Aliment. Pharmacol. Ther. 40(3), 250-260 (2014).

6 Msika S, Chastang C, Houry S, Lacaine F, Huguier M. Lymph node involvement as the only prognostic factor in curative resected gastric carcinoma: a multivariate analysis. World J. Surg. 13(1), 118-123 (1989).

7 Karpeh M, Leon L, Klimstra D, Brennan M. Lymph node staging in gastric cancer: is location more important than number? an analysis of 1038 patients. Ann. Surg. 232(3), 362-371 (2000). Cancer. In: AJCC Cancer Staging Manual. (7th Edition). Edge S, Byrd DR, Compton CC et al. (Eds). Springer, NY, USA (2010).

9 Xu D, Huang Y, Geng Q et al. Effect of lymph node number on survival of patients with lymph node-negative gastric cancer according to the 7 th edition UICC TNM system. PLoS ONE 7(6), e38681 (2012).

10 Nakagawa M, Kojima K, Inokuchi $M$ et al. Patterns, timing and risk factors of recurrence of gastric cancer after laparoscopic gastrectomy: reliable results following long-term follow-up. Eur. J. Surg. Oncol. 40(10), 1376-1382 (2014).

11 Gunderson LL, Sosin H. Adenocarcinoma of the stomach: areas of failure in a re-operation series (second or symptomatic look) clinicopathologic correlation and implications for adjuvant therapy. Int. J. Radiat. Oncol. Biol. Phys. 8(1), 1-11 (1982).

12 Shrikhande S, Barreto S, Talole S et al. D2 Lymphadenectomy is not only safe but necessary in the era of neoadjuvant chemotherapy. World J. Surg. Oncol. 11, 31 (2013).
13 Songun I, Putter H, Kranenbarg EM, Sasako M, Van De Velde CJ. Surgical treatment of gastric cancer: 15 -year follow-up results of the randomized nationwide Dutch D1D2 trial. Lancet Oncol. 11(5), 439-449 (2010).

14 Schwarz RE, Zagala-Nevarez K. Recurrence patterns after radical gastrectomy for gastric cancer: prognostic factors and implications for postoperative adjuvant therapy. Ann. Surg. Oncol. 9(4), 394-400 (2002).

15 Gholami S, Janson L, Worhunsky DJ et al. Number of lymph nodes removed and survival after gastric cancer resection: an analysis from the US Gastric Cancer Collaborative. J. Am. Coll. Surg. 221(2), 291-299 (2015).

16 Siewert JR, Bottcher K, Stein HJ, Roder JD. Relevant prognostic factors in gastric cancer: ten-year results of the German Gastric Cancer Study. Ann. Surg. 228(4), 449-461 (1998).

17 Lee HK, Yang HK, Kim WH, Lee KU, Choe KJ, Kim JP. Influence of the number of lymph nodes examined on staging of gastric cancer. Br. J. Surg. 88(10), 1408-1412 (2001).

18 Smith DD, Schwarz RR, Schwarz RE. Impact of total lymph node count on staging 
and survival after gastrectomy for gastric cancer: data from a large US-population database. J. Clin. Oncol. 23(28), 7114-7124 (2005).

19 Japanese Gastric Cancer Association. Japanese classification of gastric carcinoma: 3rd english edition. Gastric Cancer 14, 101-112 (2011).

20 Wagner PK, Ramaswamy A, Rüschoff J, Schmitz-Moormann P, Rothmund M. Lymph node counts in the upper abdomen: anatomical basis for lymphadenectomy in gastric cancer. $B r . J$. Surg. 78(7), 825-827 (1991).

21 Jiang L, Yang KH, Guan QL, Zhao P, Chen Y, Tian JH. Survival and recurrence free benefits with different lymphadenectomy for resectable gastric cancer: a meta-analysis. J. Surg. Oncol. 107(8), 807-814 (2013).

22 Mocellin S, Nitti D. Lymphadenectomy extent and survival of patients with gastric carcinoma: a systematic review and meta-analysis of time-to-event data from randomized trials. Cancer Treat. Rev. 41, 448-454 (2015).
23 Bonenkamp JJ, Hermans J, Sasako M et al. Extended lymph node dissection for gastric cancer. N. Engl. J. Med. 340(12), 908-914 (1999).

24 Bonenkamp JJ, Songun I, Hermans J et al. Randomized comparison of morbidity after D1 and D2 dissection for gastric cancer in 996 Dutch patients. Lancet 345(8952), 745-748 (1995).

25 Cuschieri A, Fayers P, Fielding J et al. Postoperative morbidity and mortality after D1 and D2 resections for gastric cancer: preliminary results of the MRC randomized controlled surgical trial. The surgical co-operative group. Lancet 347(9007), 995-999 (1996).

26 Cuschieri A, Weeden S, Fielding J et al. Patient survival after D1 and D2 resections for gastric cancer: long-term results of the MRC randomized surgical trial. Surgical co-operative Group. Br. J. Cancer 79(9-10), 1522-1530 (1999).

27 Robertson CS, Chung SC, Woods SD et al. A prospective randomized trial comparing R1 subtotal gastrectomy with R3 total gastrectomy for antral cancer. Ann. Surg. 220(2), 176-182 (1994).

28 De Bree E, Charalampakis V, Melissas J, Tsiftsis DD. The extent of lymph node dissection for gastric cancer: a critical appraisal. J. Surg. Oncol. 102(6), 552-562 (2010).

29 De Steur WO, Hartgrink HH, Dikken JL, Putter H, Van De Velde CJ. Quality control of lymph node dissection in the Dutch Gastric Cancer Trial. Br. J. Surg. 102(11), 1388-1393 (2015).

30 Sasako M, Sano T, Yamamoto S et al. D2 lymphadenectomy alone or with para-aortic nodal dissection for gastric cancer. $N$. Engl. J. Med. 359(5), 453-462 (2008).

31 Murakami T. Pathomorphological diagnosis. Definition and gross classification of early gastric cancer. Gann. Monogr. Cancer Res. 11, 53-55 (1971).

32 Barreto $S$, Windsor J. Redefining early gastric cancer. Surg. Endosc. 30(1), 24-37 (2016).

33 Shen L, Shan Y-S, Hu H-M, Price T, Sirohi B. Management of gastric cancer in Asia: resourcestratified guidelines. Lancet Oncol. 14(12), e535-e547 (2013). 